\title{
The influence of fibre pre-treatment on the mechanical properties of the geopolymer composites
}

\author{
Kinga Korniejenko ${ }^{1, *}$, Beata Figiela $^{1}$, Hana Šimonová ${ }^{2}$, Barbara Kucharczyková $^{2}$, \\ Martin Duarte Guigou ${ }^{3}$, and Michat Łach $^{1}$ \\ ${ }^{1}$ Cracow University of Technology Institute of Material Engineering, Faculty of Material Engineering \\ and Physics, Warszawska 24, 31-155 Cracow, Poland \\ ${ }^{2}$ Brno University of Technology, Faculty of Civil Engineering, Veveři 331/95, 60200 Brno, the \\ Czech Republic \\ ${ }^{3}$ Universidad Católica del Uruguay, B de Octubre 2738, CP 11600, Montevideo, Uruguay
}

\begin{abstract}
This article aims to analyse the long-term influence of the pretreatment method on mechanical properties such as the compressive strength of geopolymer composites reinforced with short natural fibres (length of around $5 \mathrm{~mm}$ ). This paper presents the behaviour of sodium activator-synthesised fly ash geopolymer containing natural fibres at ambient temperatures. Fly ash from the Skawina coal power plant (located in: Skawina, Lesser Poland, Poland) was used as a raw material. The chemical composition of the fly ash was typical for class F. The article evaluated the methods of pre-treatment of the fibres on the mechanical properties of the geopolymer composites. It compares the plain specimens and composites with fibres pre-treated in water and alkali solutions as well as with fibres without any pre-treatment. The fibres were added at the amount of $1 \%$ by weight. The investigation was made by visual analysis and the testing of mechanical properties (compressive and flexural strength at ambient temperature) after 6 months. The achieved results do not confirm the positive influence of the fibre pre-treatment on the mechanical properties of the composites.
\end{abstract}

\section{Introduction}

Nowadays, the reinforcement of geopolymers with natural fibres is an important topic, especially from an environmental point of view [1,2]. Natural fibres are environmentally friendly alternative to inorganic fibres, such as steel, carbon, glass or synthetic fibres [3, 4] in many applications, including within the construction industry $[5,6]$. They have many advantages [1, 7-9], such as:

- the reduction of greenhouse gas emissions;

- the reduction of the environmental impact (closing life cycles for products);

- the lack of toxicity;

\footnotetext{
*Corresponding author: kinga.korniejenko@pk.edu.pl
} 
- the possibility to use the same technologies as for synthetic fibres - natural fibres could replace conventional fibres in many applications without incurring additional costs;

- the low cost of production, including easy processing;

- their low density - the possibility of usage in lightweight products;

- the natural fibres are renewable in short time (usually annually).

Despite the important benefits connected with usage of natural fibres, they have also well-known disadvantages such as lower mechanical properties and dimensional repeatability than artificial fibres [10-12]. The application of natural fibres is also connected with some challenges. One of these is proper adhesion between the reinforcement and matrix [3]. Studies on fibre pre-treatment methods have been conducted as this is a strategy that offers the possibility to prevent the poor compaction of natural fibrereinforced geopolymers [3,13]. Nowadays, physical or chemical methods are applied. These methods are applied for several reasons, including to increase the surface roughness and activation of polar groups of the fibres $[3,4]$ and an adverse mechanism in the case of the hardening behaviour of the geopolymer where the surface of the hydrophilic fibres need to be treated with oil to reduce the fibre-binder interaction and minimize adhesion [14]. In the case of natural fibres, the main reason for a pre-treatment process is the removal of sugar from the fibres [13] and to reduce the influence of sugar on the matrix material by coating treatment. Examples of such methods are [3]:

- mechanical modification of the fibres, for example fibrillation and micro-indentation;

- surface modification by chemical treatment, such as alkaline and silane treatment;

- plasma modification.

In the case of geopolymer composites, only a few study have been conducted on natural-fibre modification. Zhou et al. [13] compared the effects of pre-treatment methods on cotton stalks using an alkali solution, oil, and a PVA solution. The best results were achieved for alkali treatment - compressive and flexural strengths were improved by $4.8 \%$ and $11.5 \%$, respectively, compared to untreated fibres [13]. Ngo and Promentilla confirmed the positive effect of alkali pre-treatment on abaca fibres in their research. [15]. Soaking fibres in an alkali solution (sodium hydroxide $(\mathrm{NaOH})$ ) removed the impurities from the fibres and sufficiently reduced the hydrophilic components in the abaca fibres [15]. This was evident in TGA results.

The above-mentioned studies have shown the potential of pre-treatment on enhancing the adhesion of fibres to the matrix. The article evaluated the different methods of pretreatment of flax fibres on the mechanical properties of the geopolymer composites. It compares the plain specimens and composites with fibres pre-treated in water and alkali solutions as well as with fibres without any pre-treatment.

\section{Materials and methods}

\subsection{Materials}

As a raw material for geopolimerisation, fly ash from the CHP plant in Skawina was used (Lesser Poland region, Poland). The physical and chemical properties of this fly ash are appropriate for geopolymer manufacturing [16, 17]. The composition of this material is characteristic for class $\mathrm{F}$ (up to $5 \%$ of unburned material, less than $10 \%$ of iron compounds and a low amount calcium compounds). It comprises $36 \%$ of the reactive silica and the content of particles under a size of $45 \mu \mathrm{m}$ is around $88 \%[16,17]$. These factors are important for the proper reactivity of the raw material. The good workability of fly ash is 
caused by it having a large amount of spherical particles (Fig. 1). The investigation of the mineralogical structure shows a large amount of the amorphous phase [17].
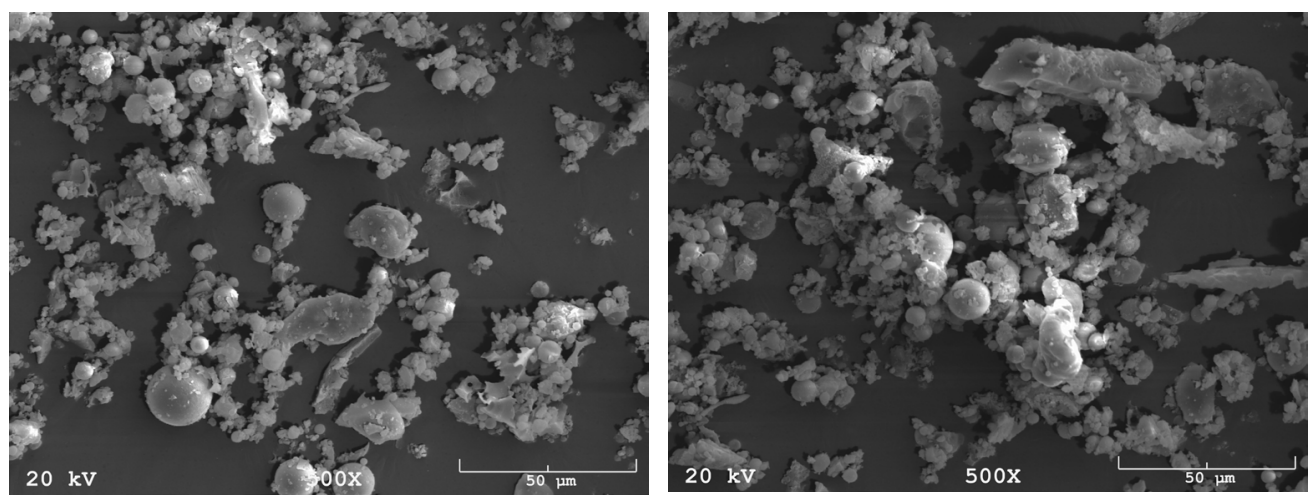

Fig. 1. SEM images for fly ash at 500x magnification

The samples were reinforced with $1 \%$ by mass of green tow flax fibres. These flax waste fibres were chosen because it is one of two fibre plants naturally occurring in Poland, the other being hemp. The green tow flax fibre is a coarse, broken fibre which is removed during flax processing - it is a by-product of textile-fibre production. This fibre is rather thin, has moderate stiffness and it is usually shorter than $30 \mathrm{~cm}$. For the research fibres not longer than $0.5 \mathrm{~cm}$ were applied - they were mechanically shortened. The fibres have been purchased from the Institute of Natural Fibres and Medicinal Plants in Poland.

\subsection{Sample preparation}

Samples were prepared using fly ash, flax fibres and a $12 \mathrm{M}$ ratio of sodium hydroxide solution. The fly ash, alkaline solution and fibres were manually mixed for around 5-10 minutes to obtain a homogeneous paste. The homogeneous paste was then transferred into sets of plastic moulds and was hand-formed. Next, the composites were heated in the laboratory drying cabinet for $24 \mathrm{~h}$ at $75{ }^{\circ} \mathrm{C}$. Afterward, the samples were unmoulded. The six series of prepared samples are presented in Table 1.

Table 1. The information about prepared samples

\begin{tabular}{|c|c|}
\hline Sample & Reinforcement \\
\hline 00 & Sample without fibre \\
\hline F0 & $1 \%$ flax fibre without pre-treatment \\
\hline F1 & $1 \%$ flax fibre: pre-treatment 24 hours in distilled water \\
\hline F2 & $1 \%$ flax fibre: pre-treatment 24 hours in sodium alkali 3 moles \\
\hline F3 & $1 \%$ flax fibre: pre-treatment 24 hours in sodium alkali 6 moles \\
\hline F4 & $1 \%$ flax fibre: pre-treatment 24 hours in sodium alkali 12 moles \\
\hline
\end{tabular}

The samples were stored in laboratory conditions for 6 months. Next, research of the mechanical properties was conducted. 


\subsection{Methods}

Compressive strength testing was performed after 6 months on cubic samples of the following dimensions: 50 × $50 \times 50 \mathrm{~mm}$. The tests were provided in accordance with methodology described in the EN 12390-3 standard. The testing process was performed on a MATEST $3000 \mathrm{kN}$ concrete press at a rate of $0.5 \mathrm{MPa} / \mathrm{s}$. The tests involved four specimens of each group of samples.

Flexural strength tests were performed after 6 months on prismatic samples of the following dimensions: $50 \times 50 \times 200 \mathrm{~mm}$ (the space between supporting points was $150 \mathrm{~mm}$ ). The tests were conducted in accordance with the methodology described in the EN 12390-5 standard. The testing process was performed on a MATEST 3000kN universal testing machine at a rate of $0.05 \mathrm{MPa} / \mathrm{s}$. The tests involved eight specimens of each group.

\section{Results}

The results of the compressive strength tests are presented in Table 2.

Table 2. The results of compressive strength tests

\begin{tabular}{|c|c|c|}
\hline Sample & $\begin{array}{c}\text { Compressive } \\
\text { strength [MPa] }\end{array}$ & Standard deviation \\
\hline 00 & 50.2 & 3.3 \\
\hline F0 & 46.1 & 4.1 \\
\hline F1 & 40.5 & 9.2 \\
\hline F2 & 35.9 & 4.5 \\
\hline F3 & 36.5 & 13.2 \\
\hline F4 & 23.0 & 7.1 \\
\hline
\end{tabular}

The best results were achieved for the samples without fibre $-50.2 \mathrm{MPa}$. These results were very similar to the composite with $1 \%$ flax fibre without pre-treatment. The results for the composites for which the fibres received pre-treatment for 24 hours in distilled water or in sodium alkali were significantly worse. They had lower values of compressive strength as well as large standard deviations. The results for particular samples had significantly different values.

The results of the flexural strength tests are presented in Table 3.

Table 3. The results of flexural strength tests

\begin{tabular}{|c|c|c|}
\hline Sample & $\begin{array}{c}\text { Flexural } \\
\text { strength [MPa] }\end{array}$ & Standard deviation \\
\hline 00 & 6.2 & 0.4 \\
\hline F0 & 6.0 & 0.5 \\
\hline F1 & 5.3 & 1.0 \\
\hline F2 & 5.3 & 0.6 \\
\hline
\end{tabular}




\begin{tabular}{|c|c|c|}
\hline F3 & 3.0 & 2.0 \\
\hline F4 & 3.0 & 0.5 \\
\hline
\end{tabular}

The flexural strength tests give similar results as compressive strength tests. The best results were achieved for the samples without reinforcement $-6.2 \mathrm{MPa}$. In this case, it is quite surprising because the fibre addition should increase the bending value. Similar results were obtained for the composite with $1 \%$ flax fibre without pre-treatment 6.0 MPa. Significantly worse values were obtained for the composites with $1 \%$ flax fibre: pre-treatment 24 hours in distilled water and in sodium alkali of 3 moles - 5.3 MPa. Pretreatment for 24 hours in sodium alkali of 6 moles and 12 moles had a negative influence on flexural strength. The results for these samples were only 3.0 MPa.

The results of the compressive strength test were compared with sample density (Table 4).

Table 4. The results of density

\begin{tabular}{|c|c|}
\hline Sample & Density $\left[\mathrm{g} / \mathrm{cm}^{3}\right]$ \\
\hline 00 & 1.47 \\
\hline F0 & 1.49 \\
\hline F1 & 1.44 \\
\hline F2 & 1.36 \\
\hline F3 & 1.40 \\
\hline F4 & 1.41 \\
\hline
\end{tabular}

The density should be correlated with compressive and flexural strength for the composites. For the examined samples, this tendency appears to a slight extent. The samples without fibre and with $1 \%$ flax fibre without pre-treatment have higher density values and also better mechanical properties. The samples with fibres pre-treated for 24 hours in sodium alkali solutions have lower densities and lower mechanical properties. In this case, the advantages connected with lower density are not as important as the significantly lower values of mechanical properties, especially for composites with $1 \%$ flax fibres pre-treated for 24 hours in the sodium alkali of 12 moles.

\section{Discussion}

The results for compressive and flexural strength are closely related. The highest results were obtained for the samples without reinforcement and for the composite with $1 \%$ flax fibre without pre-treatment. It shows that the process of pre-treatment does not improve the mechanical properties of the composites. These results are not coherent with the investigation of other cellulose-based fibres $[13,15]$. Usually, the chemical treatment of fibres, such as alkalisation, improves cellulosic-fibre tensile properties and positively influences composite mechanical properties [3, 13]. The results for pre-treated fibres are significantly worse and the worst results are for the fibres pre-treated in sodium alkali of 12 moles. This could be explained by decreasing the cross section of the fibres which affects the mechanical properties of the composites. However, such mechanism was not 
observed in the adopted solutions for flax fibres. The investigations did not showed visible micro cracks due to water or solution absorption on the surface of the material. Some explanation of this mechanism could be existence in the waste material some coarse elements that appeared after the process of flax fibres manufacturing.

The achieved results for reinforcement are also not fully in line with other investigations made for flax-fibre additives. The addition of natural fibres should increase flexural strength and decrease density [3, 10]. For example, the research provided by Assaedi et al. [19] shows that both flax and cotton fibres enhanced the mechanical strengths of geopolymer matrices $[10,19]$. In the case of the provided test, the results for reinforced materials and plain samples do not show significant differences. The same mechanism was observed on different matrices based on: dehydroxylated kaolinite-type clay (New Zealand halloysite - Imerys Premium grade) [20], low calcium fly ash (from the Eraring power station in NSW) [21, 22] and fly ash with nano-clay particles [23, 24]. All this studies confirmed that the addition of flax fibres between 4 and $10 \%$ by mass increased the mechanical properties of the composites. Other research shows that a lower amount of reinforcement $(0.25-1.0 \%$ by mass) also positively influences the mechanical properties, especially the flexural strength of the geopolymer fly ash-based composites [25]. The mechanism of reinforcement could be related to the kind of flax fibres used $[18,26]$. A lot of advantages could lead to the application of long flax fibres or flax fabric as reinforcement $[27,28]$.

\section{Conclusions}

The main goal of article was to improve the interfacial bonding properties of flax fibres by pre-treatment and thus increase mechanical properties. The research shows that pretreatment methods such as 24 hours in distilled water and 24 hours in sodium alkali at different molar ratios are not ineffective. The results of both compressive and flexural strength tests were lower than for material without reinforcement and the composite with $1 \%$ flax fibre without pre-treatment. This shows that these kinds of methods are inappropriate for flax fibres. The research could be continued with the use of different pretreatment methods.

This work has been financed by the Polish National Agency for Academic Exchange under the International Academic Partnership Programme within the framework of the grant: E-mobility and sustainable materials and technologies EMMAT (PPI/APM/2018/1/00027) and in the framework of bilateral exchange of researchers between Poland and the Czech Republic with the grant: Fibers Reinforced Geopolymers (PPN/BCZ/2019/1/00005/U/00001, the Czech designation 8J20PL073).

\section{References}

1. G. Silva, S. Kim, R. Aguilar, J. Nakamatsu, Sustainable Mat. Techn. 23, e00132 (2020)

2. K. Korniejenko, M. Łach, N. Dogan-Saglamtimur, G. Furtos, J. Mikuła, Environmental Research \& Technology 3 (1), 28 (2020)

3. N. Ranjbar, M. Zhang, Cem. Concr. Comp. 107, 103498 (2020)

4. L. Yan, B. Kasal, L. Huang, Comp. Part B 92, 94 (2016)

5. D. Castañeda, G. Silva, J. Salirrosas, S. Kim, B. Bertolotti, J. Nakamatsu, R. Aguilar, Constr. Build. Mat. 253, 119143 (2020)

6. K. Korniejenko, E. Frączek, E. Pytlak, and M. Adamski, Procedia Eng. 151, 388 (2016) 
7. A. M. Rashad, Natural Resources Conservation \& Research 1, 9 (2018)

8. G. Furtos, L. Silaghi-Dumitrescu, P. Pascuta, C. Sarosi, K. Korniejenko, J. Natural Fibers 1 (2019)

9. K.M. Liew, A.O. Sojobi, L.W. Zhang, Constr. Build. Mat. 156, 1063 (2017)

10. A. R. Sakulich, Sustainable Cities \& Society 1, 195 (2011)

11. R. M. Novais, R.C. Pullar, J.A. Labrincha, Progress in Materials Sci. 109, 100621 (2020)

12. A. Wongsa, R. Kunthawatwong, S. Naenudon, V. Sata, P. Chindaprasirt, Constr. Build. Mat. 241, 118143 (2020)

13. B. Zhou, L. Wang, G. Ma, X. Zhao, X. Zhao, J. Cleaner Production 245, 118842 (2020)

14. B. Nematollahi, J.S. Qiu, E.H. Yang, J. Sanjayan, Ceramics Int. 43 (17), 15616 (2017)

15. J. P. S. Ngo, M. A. B. Promentilla, MATEC Web Conf. 156, 05018 (2018)

16. K. Korniejenko, N. P. Halyag, G. Mucsi, IOP Conf. Series: Mat. Sci. \& Eng. 706, 012002 (2019)

17. K. Korniejenko, M. Łach, J. Marczyk, C. Ziejewska, N.P. Halyag, G. Mucsi, IOP Conf. Series: Mat. Sci. \& Eng. 706, 012006 (2019)

18. K. Korniejenko, M. Łach, M. Hebdowska-Krupa, J. Mikuła, IOP Conf. Series: Mat. Sci. \& Eng. 379, 012023 (2018)

19. M. Low (ed.) Advances in Ceramic Matrix Composites (Woodhead Publishing, 2018)

20. M. Alzeer, K. MacKenzie, Applied Clay Sci. 148 75-76, (2013)

21. H. Assaedi, T. Alomayri, F. U. A. Shaikh, I.M. Low, Advances in Materials Res. 3, 151 (2014)

22. H. Assaedi, T. Alomayri, F.U.A. Shaikh, I.M. Low, J. Adv, Ceramics 4, 272 (2015)

23. H. Assaedi, F. U. A. Shaikh, I.M. Low, Comp. Part B 95, 412 (2016)

24. H. Assaedi, F. U. A. Shaikh, I.M. Low, J. Asian Ceramic Societies 5, 62 (2017)

25. G. Lazorenko, A. Kasprzhitskii, A. Kruglikov, V. Mischinenko, V. Yavna, Ceramics Int. 46, 12870 (2020)

26. G. Silva, S. Kim, A. Castañeda, R. Donayre, J. Nakamatsu, R. Aguilar, K. Korniejenko, M. Łach, J. Mikuła, IOP Conf. Series: Mat. Sci. \& Eng. 416, 012107 (2018)

27. M. Frydrych, Š. Hýsek, L. Fridrichová, S.L. Van, M. Herclík, M. Pechociaková, H. L. Chi, P. Louda, Sustainability 12, 118 (2020)

28. H. Assaedi, T. Alomayri, F. Shaikh, I.-M. Low, Materials 12, 1459 (2019) 